\title{
QUALIS PERIÓDICOS: VISÃO DO ACADÊMICO NA GRADUAÇÃO MÉDICA
}

\author{
Adson Freitas de Lucena ${ }^{1 *}$, Rachel Vasconcelos Tibúrcio ${ }^{2}$ \\ Trabalho realizado na Faculdade de Medicina da Universidade Federal do Ceará, Sobral, CE
}

*Correspondência:

102 A - Derby Clube

Sobral - CE

CEP: 62042-210

Email: adsonbr@gmail.com

\section{RESUMO}

A classificação QUALIS para o sistema nacional de pós-graduação hoje adota um novo método de ranqueamento desenvolvido para análise de seus periódicos e programas, que pouco se prende à questão da qualidade da produção científica. 0 campo acadêmico impõe tantas nuances de qualidade que os ideais de quantificação para avaliação das publicações têm suscitado a justificada insatisfação de muitos. Compreendemos que avaliar a formação acadêmica deve ser um objetivo corrente das instituições de ensino que incorporam graduação e pós-graduação. Nessa concepção, a qualidade é uma peça fundamental para o desenvolvimento de habilidades e competências de uma sociedade em constante transformação. Transmutar esse sistema de avaliação, exigindo dos acadêmicos competências pedagógicas e científicas que nem sempre procedem da atividade de pesquisa, possibilitará um maior desenvolvimento no plano institucional, docente e discente.

Unitermos: Programas de Pós-Graduação em Saúde. Ensino. Avaliação institucional.
Existem duas principais dimensões na área da produção científica acadêmica: a primeira é a eficiência, ou seja, a relação entre os recursos humanos disponíveis e a capacidade per capita de produzir pesquisa e ensino; a segunda é a qualidade das publicações, sobretudo da pesquisa. O valor de uma publicação é baseado no QUALIS, definido pela Coordenação de Aperfeiçoamento de Pessoal de Nível Superior (CAPES) como uma base de dados utilizados para a divulgação da produção intelectual dos programas de pós-graduação stricto sensu. Até recentemente, esses veículos eram classificados quanto ao âmbito de circulação e quanto à qualidade, para cada área de avaliação. A classificação QUALIS passou a ser o parâmetro avaliatório da produção científica pelas agências de fomento e para a análise de professores pelas instituições de ensino. Essa avaliação vem se tornando uma preocupação frequente para os pesquisadores do País, principalmente pela exigência de classificar profissionais competentes para a pesquisa e para o exercício da docência².

O portal de livre acesso da CAPES disponibiliza publicações gratuitas, por vinculação digital, selecionadas pelo nível de relevância acadêmica ${ }^{4}$. Entretanto, essa importante função adotada pela CAPES vem sendo comprometida pelo novo método de ranqueamento criado para análise de seus periódicos e programas desenvolvidos nos anos de 2007 a 2009, que pouco se prende à questão da qualidade da produção científica. Essa classificação teve sua importância como primeira medida de qualificação das produções advindas da pós-graduação, contudo, é corrente o pensamento que seu ciclo de validade já se esgotou e deve ser substituída².
O sistema QUALIS de apreciação, continuamente aperfeiçoado, deveria ser instrumento propulsor para a comunidade universitária na busca de um padrão de excelência acadêmica para os mestrados e doutorados nacionais, refletindo sobre a orientação e o ensino científico da graduação médica. É notório o paradoxo hoje observado nas ações desenvolvidas pela CAPES ao apoiar o financiamento de periódicos brasileiros e prejudicá-los com um sistema falho avaliação.

A atualização sobre novos conhecimentos em medicina é mandatória para desenvolver projetos de pesquisa relevantes em vários momentos da graduação médica ${ }^{1}$. Os periódicos, artigos de revisão e bibliografias tornaram-se mais acessíveis após o advento da internet, permitindo à comunidade acadêmica uma importante concatenação e formatação do conhecimento contemporâneo. É fácil perceber o quão pernicioso pode ser a qualificação errônea de uma publicação em um meio de amplo acesso de pesquisa, já que esta poderá servir como base bibliográfica para um projeto acadêmico. Faz-se necessário, então, uma política nacional adequada de avaliação de periódicos para ampliar o embasamento do estudo acadêmico e promover as instâncias científicas que publicam materiais de qualidade.

O graduando de medicina, ao longo do seu curso, entra em contato com a pesquisa médica tendo a oportunidade de ingressar em projetos de iniciação científica, de pesquisa e de extensão acadêmica. Com uma equipe de professores pós-graduados a auxiliar os graduandos, percebemos que a política de avaliação da pós-graduação e os critérios por ela estabelecidos em vigor influenciam diversas esferas da ordem acadêmica. A avaliação 
da produção de pesquisadores tal como se apresenta, pode ofuscar sua qualificação, tolhendo seu merecimento de bolsas de auxílio em busca de desenvolvimento científico. Percebe-se que o acadêmico seria prejudicado, pois perderia em parte a dedicação de seu tutor e deixaria de ser auxiliado financeiramente pelo seu empenho. É importante salientar que a pesquisa e as publicações delas engrendradas podem não ser apreciações de mérito, sendo questionável a premissa de serem indicadores da qualidade do ensino na graduação e na pós-graduação.

O campo acadêmico impõe tantas nuances de qualidade que os ideais de quantificação para avaliação das publicações têm suscitado a justificada insatisfação de muitos ${ }^{3}$. A legalidade de um dos mais importantes parâmetros de avaliação de professores, atualmente considerado pelas instituições de ensino, está comprometida, afinal algumas premissas do QUALIS periódicos não guardam qualquer relação específica com a qualidade das publicações.

Em suma, compreendemos que avaliar a formação discente e docente deve ser um objetivo corrente das instituições de ensino que envolve graduação e pós-graduação. Qualificar acadêmicos e profissionais por meio de competências científicas para as diferentes matizes do conhecimento é elementar para o progresso do ensino brasileiro. Portanto, técnicas e sistemas para mensurar a excelência de formação devem abranger aspectos qualitativos e quantitativos em proporções e valores similares, além de permitir adaptações sensíveis para apreciar as diversas áreas do conhecimento científico ${ }^{3}$. Nessa concepção, a qualidade é uma peça fundamental para o desenvolvimento de habilidades e competências de uma sociedade em constante transformação. Modificar esse sistema de avaliação, exigindo competências pedagógicas e científicas que nem sempre procedem da atividade de pesquisa², possibilitará um maior desenvolvimento no plano institucional, docente e discente. Dessa forma, as entidades federais terão um sistema de verificação que efetivamente possa propor melhorias na qualidade educacional, gerando desafios para modificar o regimento universitário ao sabor das novas tendências mundiais que priorizam a aptidão técnica, a responsabilidade social, a ética e a excelência científica contínua.

\section{SUMmARY}

QUALIS PERIODICAL: VIEW OF AN ACADEMIC ON MEDICAL GRADUATION

The QUALIS classification for the national system of postgraduation has currently adopted a new ranking method developed for analysis of their periodicals and programs that has little to do with the quality of scientific production. The academic field involves so many subtleties of quality that the ideal of quantification to assess publications has aroused the justified dissatisfaction of many.. We understand that the assessment of academic training must be a current goal of educational institutions that provide graduation and post-graduation. . Under this concept, quality is a key to the development of abilities and skills of a society in constant transformation. To modify this system of assessment requiring from academics teaching and scientific skills that do not always result from research activity, will further development on the institutional, faculty and student level. .

KEY WORDS: Teaching care integration services. Systems for evaluation of publications. Institutional evaluation.

\section{REFERÊNCIAS}

1. Barreto ML. A pesquisa em Saúde Coletiva no Brasil. Cad Saúde Pública 2003;19(2):354-55.

2. Rocha-e-Silva M. O novo Qualis, ou a tragédia anunciada. [cited 2009 Feb 3] Clinics. 2009;64(1):1-4. Available from: http://www.scielo.br/scielo. php?script $=$ sci_arttext\&pid=S1807-59322009000100001\&lng=en. doi: 10.1590/S1807-59322009000100001.

3. Luiz RR. Avaliação de produtividade acadêmica: uma proposta de quantificação. RBPG. Rev Bras Pós-Graduação. 2006;6(3):300-12.

4. Hortale VA. CAPES evaluation model: desirable and necessary, but incomplete. [cited 2009 Feb 2]. Cad Saúde Pública. 2003;19(6):1837-1840. Available from: http://www.scielo.br/scielo. php?script=sci_arttext\&pid=S0102-311X2003000600027\&Ing=en 